\title{
Incidental diagnosis of primary papillary carcinoma arising from thyroglossal duct cyst: A rare case report
}

\author{
Mukta Rawte', Nabaneet Majumder ${ }^{1}$, Virendra Dafle ${ }^{2}$, Pramod Purohit ${ }^{3}$ \\ ${ }^{1}$ Post-Graduate Student, ${ }^{2}$ Assistant Professor, Department of Pathology, Dr DY Patil Medical College, Kolhapur, ${ }^{3}$ Consulting Pathologist, \\ Purohit Laboratory, Station Road, Kolhapur
}

\section{A B S T R A C T}

Thyroglossal duct cysts are most common congenital anomalies in thyroid development and are usually presented with midline neck swelling. The co-existence of carcinoma in thyroglossal duct cyst's is extremely rare. We, herein present a case of primary papillary carcinoma arising from thyroglossal duct cyst in a 45 year old woman.

Access this article online

Website:

http://nepjol.info/index.php/AJMS

Key words: Thyroglossal duct cyst, Papillary carcinoma, Midline neck swelling

\section{INTRODUCTION}

Thyroglossal duct cysts are the most common developmental anomalies of thyroid gland. The thyroid gland develops from the floor of the primitive pharynx during the third week. The thyroid gland descends from its origin in $4^{\text {th }}$ week of embryogenesis. During this descent, the connection between thyroid gland and foramen cecum may persist to form thyroglossal duct. They are usually benign, but approximately $1 \%$ of them may develop neoplastic changes. Carcinoma arising in TDC is rare and characterised by a relatively non aggressive behaviour with rare lymphatic spread. ${ }^{1}$ Thyroglossal duct cysts are the most common congenital cervical abnormality in childhood, with a frequency of $70 \%$ and about $7 \%$ in adults. The condition is more common in women than in men $(1.5: 1){ }^{2}$ The first description of a neoplasm in a thyroglossal duct cyst was given by Brentano in 1911 and Uchermann in 1915. ${ }^{3}$ The cysts commonly present as asymptomatic midline neck swellings and the presentation of the patient with carcinoma is indistinguishable from the common cyst. Thus carcinoma is not suspected preoperatively and most cases are diagnosed as thyroglossal duct cysts. ${ }^{3}$

\section{CASE REPORT}

A 45 year old female presented with the complaint of an anterior midline neck swelling since 10 years without any symptoms. The physical examination revealed a midline smooth, painless, cystic swelling of size $3 \times 2 \times 1 \mathrm{~cm}$. Swelling moved on deglutination. Ultrasonography of the swelling was suggestive of thyroglossal duct cyst. Clinical examination coupled with biochemical and radiological assay suggested no thyroid abnormality. On fine needle aspiration cytology of the cystic swelling, microscopic examination revealed few macrophages and lymphocytes on the background of eosinophilic material (Figure 1). Taking clinical findings into consideration, the FNAC diagnosis was given as thyroglossal duct cyst, following which sistrunk procedure was performed. Grossly, the resected specimen was a single cystic mass measuring $3 \times 2 \times 1 \mathrm{~cm}$. Inner aspect of the cyst wall was whitish and smooth which showed a focal thickened area and an irregular indistinct mass. The cut surface of the mass was light brown to pale in colour. Specimen was examined thoroughly and multiple sections were taken for histopathological study. Microscopically, sections from the cyst showed fibrocollagenous cyst wall lined by low columnar to cuboidal epithelium (Figure 2). Sections from the mass showed a tumor composed of round to cuboidal cells arranged in papillae, follicles and clusters. Cellular crowding with nuclear overlapping, clearing, and grooving were noted. Foci of calcification and occasional psammoma body were seen.

On the basis of gross and microscopic findings the histopathological diagnosis of 'Papillary thyroid carcinoma' of thyroglossal duct cyst was given. 


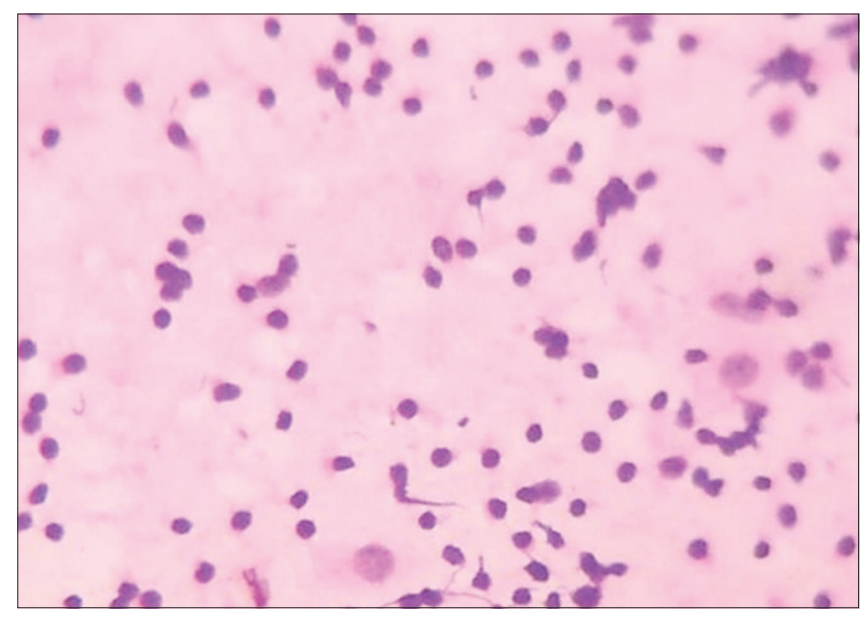

Figure 1: Microphotograph showing macrophages and lymphocytes over eosinophilic background on aspiration cytology (H \& E, 40x)

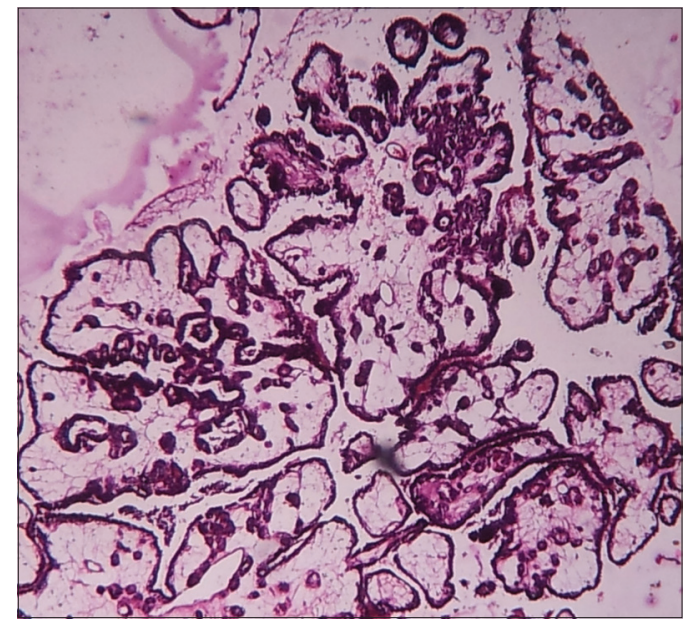

Figure 2: Microphotograph of tumour showing predominantly papillary arrangement $(\mathrm{H} \& \mathrm{E}, 10 \mathrm{x})$

Regular post-operative follow up was possible in our case up to two years at regular intervals which showed no evidence of local recurrence, lymphadenopathy or any changes in thyroid gland. Thyroxine suppression therapy was also given with a dose of $50-100 \mathrm{mg} /$ day.

\section{DISCUSSION}

Thyroglossal duct cyst is the most common benign cervical mass except for benign cervical lymphadenopathy. They present as a cystic midline neck mass that elevates with swallowing and protrusion of tongue. The cyst may be located anywhere along the course of the thyroglossal duct cyst. Thyroglossal duct cyst carcinoma are rare with just more than 250 cases published till date. ${ }^{4}$

Malignant tumors developing from the thyroglossal duct have two origins: thyrogenic carcinoma arising from thyroembrionic remnants in the duct or a cyst, and squamous cell carcinoma arising from metaplastic columnar cells that line the duct. Excluding medullary carcinoma, which arises from parafollicular cells embryologically unrelated to the thyroid, all forms of primary thyroid carcinoma can arise in the thyroglossal duct. ${ }^{5}$

The results in the literature show that papillary carcinoma is the most common type $(80 \%)$, followed by "mixed" papillary-follicular carcinoma(8\%) and squamous cell carcinoma $(6 \%)$. The remaining $6 \%$ include rare cases of hurtle cell, follicular and anaplastic carcinomas. ${ }^{6}$

Widstrom et $\mathrm{al}^{6}$ suggested two, histopathologic diagnostic criteria for primary carcinoma of thyroglossal cyst: the localization of the carcinoma to a clearly demonstrable thyroglossal duct and the absence of carcinoma on histopathologic examination of the thyroid gland. In our case the thyroid gland was not subjected to histopathological examination as intra-operatively no thyroid abnormality was detected on gross examination.

Regional lymph node metastasis of thyroglossal duct cyst carcinoma occur in only $7.7 \%$ of reported cases, and local invasion rarely occurs. A rapid increase in size, the occurrence of pain and the presence of enlarged lymph nodes may suggest malignancy. ${ }^{7}$ The risk factors for this type of carcinoma are not sufficiently studied, but radiation of the neck is a possible risk factor as it is for the papillary carcinoma of thyroid gland. ${ }^{8}$

The treatment of the most common midline cervical mass is Sistrunk procedure, which was also performed in our case. In the Sistrunk procedure the mass and canal is carefully dissected within the body of hyoid bone up to the foramen cecum. ${ }^{?}$

The overall prognosis of all histological subtypes of thyroglossal duct cyst carcinoma is good except for squamous cell carcinoma which caries poor prognosis with a mortality rate of $30-40 \%{ }^{1,10}$

\section{CONCLUSION}

We reported a case of thyroglossal duct cyst carcinoma to highlight the possibility of such lesion arising from thyroglossal duct cyst, as it is very rare and patients are often asymptomatic. Thus along with high index of suspicion, careful pathological examination is indicated in these cases as they carry excellent prognosis with early detection.

\section{REFERENCES}

1. Nadimi-tehrani A, Karimi-yazdi AR and Kazemi M. Primary papillary carcinoma in thyroglossal duct cyst. Acta Medica Iranica 2007;45(3):236-238. 
2. Martins AS, Demelo GM, Tincani AJ, Lage HT and Dematos PS. Papillary carcinoma in a thyroglossal duct: case report. Sau Paulo Med J/Rev Paul Med 1999;117(6):248-250.

3. Shelke VN and Raut WK. Papillary thyroid carcinoma of thyroglossal duct cyst: a case report and review of the literature. Journal of Pathology of Nepal 2012; 2:328-330.

4. Neupane $Y$ and Paudel DR. Carcinoma in a thyroglossal duct cyst. Nepalese Journal of ENT Head and Neck Surgery 2012;3(1):24-26.

5. Kandogan $\mathrm{T}$, Erkan $\mathrm{N}$ and Vardar E. Papillary carcinoma arising in a thyroglossal duct cyst with associated micro carcinoma of the thyroid and without cervical lymph node metastasis: A case report. Journal of Medical Case Reports 2008;2:42.
6. Chu YC, Han JY, Han HS, Kim JM, Min SK and Kim YM. Primary papillary carcinoma arising in thyroglossal duct cyst. Yonsei Medical Journal 2002;43(3):381-384.

7. Aghaghazvini L, Mazaher $\mathrm{H}$, Sharifian $\mathrm{H}$, Aghaghazvini $\mathrm{S}$ and Assadi M. Invasive thyroglossal duct cyst papillary carcinoma: A case report. Journal of Medical Case Reports 2009;3:9308.

8. Zivaljevic $V$ and Bozic V. Papillary carcinoma in a thyroglossal duct cyst. Acta Chir Belg 2006;106:252-253.

9. Eryilmaz MA and Toy $\mathrm{H}$. Primary papillary thyroid carcinoma in the thyroglossal cyst. Eur J Gen Med 2011;8(1):69-71.

10. Balalaa N, Megahed M, AI Ashari M and Branicki F. Thyroglossal duct cyst papillary carcinoma. Case Rep Oncol 2011;4:39-43.

\section{Authors Contribution:}

MR and NM - Concept and design of study; MR, NM, VD - Drafting the article or revising it critically for important intellectual content; PP - Final approval of the version to be published.

Source of Support: Nil, Conflict of Interest: None declared. 